\title{
LA CONTRIBUCIÓN DEL IDEALISMO FENOMENOLÓGICO A LA RESTAURACIÓN DEL REALISMO
}

La disputa entre el realismo y el idealismo fue un tema candente de la filosofía hacia fines del siglo xix y en los primeros decenios del presente. $Y$ digo "fue", porque la disputa puede considerarse aplacada por la anulación, en cierto aspecto, del problema que le dio origen, desde que Heidegger en SZ describió al Dasein humano como un ser en el mundo. ${ }^{1}$

En aquella discusión el contrincante que reaparecía con nuevo vigor era el realismo, puesto que el idealismo engarzaba casi sin solución de continuidad en la tradición de la filosofía moderna que, desde Descartes, con excepción de los brotes esporádicos de materialismo y del desierto filosófico del positivismo, era idealista.

Al idealismo, representado sobre todo por un lado por los que respondian a la inspiración del empirismo inglés, como Schuppe y Avenarius, y por otro, por los que seguían las trazas de Kant, como Rickert y Cohen, se oponen, al lado del renaciente tomismo, pero independientemente de él, el realismo volitivo de Dilthey, el realismo crítico de Külpe y el realismo ontológico de N. Hartmann, para no citar sino a sus representantes más señalados.

$Y$, sin embargo, por una de esas paradojas no raras en la historia del pensamiento, es la fenomenologia de Husserl, que según su autor es la prueba y no puede separarse del idealismo trascendental, la que más ha contribuido, en mi entender, a la restauración del realismo, porque ha descubierto el punto en donde arraiga el error que origina al idealismo y que, sorprendentemente, es también el supuesto del neorrealismo, que se ve en la necesidad de demostrar la existencia del mundo exterior, tarea en la que siempre fracasa porque cabalmente no ha desarraigado ese supuesto.

El punto en cuestión es la interpretación de la conciencia, especialmente en lo que se refiere a la percepción. Pero para apreciar su significado es preciso conocer los antecedentes del problema.

Todo hombre en la actitud natural es realista. Esto significa la asunción de una doble tesis: I) que las cosas en general y el mundo existen fuera

1 En nuestro pais la discusión apenas encontró eco, a causa de la predominancia, primero, de las doctrinas positivistas, y luego, de la filosofía de Bergson, la cual, si bien trata el problema y se inclina por el lado del realismo, no constituye un punto central de su doctrina, por lo cual pasó inadvertido. Una teoría idealista, sólo puede encontrarse, que yo sepa, en los escritos de Fernando Beltramo, que se halla bajo la influencia del idealismo italiano. 
e independientemente de él; 2) que el objeto del conocimiento son esas mismas cosas en general y el mundo. No es que el hombre afirme esa doble tesis: al contrario, no siente la necesidad de afirmarla, porque no se plantea el problema, sólo respecto al cual tendria sentido la misma afirmación. Es simplemente el supuesto a priori de toda su conducta teórica y práctica, de toda experiencia de las cosas y de toda operación sobre ellas. El hombre se halla rodeado de un mundo de entes reales, en el cual nace, vive y muere. Él mismo es un ente entre los entes. Los conoce con los sentidos, pero sin suponer ninguna mediación entre ellos y él. El conocimiento toca, por así decirlo, a las cosas mismas. El realismo natural se puede esquematizar por medio de dos círculos que se tocan, uno de los cuales representa al hombre y otro a la cosa-objeto:



Sin duda, el hombre se plantea el problema de si existe tal o cual cosa o si no era, más bien, una ilusión o una creencia sin fundamento; o si la cosa era tal y como le fue dada en determinada situación, y no más bien tal y como se le presenta en otra situación que considera más adecuada. Pero esto atañe sólo a casos particulares. Y nunca abandona la tesis general de que existe el mundo y que éste es cognoscible tal como es.

También sería una interpretación desviada pensar que el realismo natural fuera la actitud del hombre vulgar, pero no la del filósofo. Éste participa de ella tanto como aquél, justamente porque el realismo no es el resultado de una afirmación teórica, sino un factum primario de la conciencia, un supuesto de toda afirmación o negación sobre las cosas. La filosofía lo puede interpretar, ratificar, corregir o refutar. Pero cualquiera que sea su solución, la actitud realista mantendrá su vigencia, pues, por ser un factum, es indestructible.

Si de la actitud natural pasamos a la consideración de la filosofía, comprobamos que ya en la Antigüedad se introdujo un tercer término entre el cognoscente y lo conocido, esto es, la imagen. Tal es el éidolon de Empédocles y los atomistas y la fantasia de Protágoras, estoicos y escépticos. Pero no nos detendremos en estas doctrinas sino en la aristotélico-tomista, porque ella constituye el trasfondo necesario para comprender por contraposición la tesis cartesiana.

No cabe ninguna duda que Aristóteles admite una imagen o idea de la 
cosa en el sujeto: es lo que él llama "eidos" o "morphe", y que traducimos comúnmente con la palabra "forma". Los textos son bien conocidos: "el sentido es el receptáculo de las formas sensibles sin la materia" (De an. II, 424a 18). "No es la piedra la que está en el alma sino su forma" (id. III, $431 \mathrm{~b} 29$ ). Por su parte, el intelecto es susceptible de recibir las formas inteligibles (id. III, 429a 15). La cosa produce en el alma una modificación que es la forma: "el acto del agente y del motor se producen en el paciente" (III, 426a 5); "el acto del sensible y el acto de la facultad sensible residen en el que siente" (III, 426a 10). Es por ello por lo que Aristóteles puede decir que el intelecto es la forma de las formas y el sentido, forma de los sensibles (III, 432a 2), y en general, que el alma es el lugar de las formas (III, 429a 2).

Pero el punto que nunca debe perderse de vista en la gnoseología aristotélica es que, a pesar de que en el alma se producen las formas sensibles e inteligibles de las cosas, el objeto del conocimiento no son aquéllas, sino las cosas mismas. Esto es lo que resulta de otros textos no menos conocidos. En cuanto a la sensación, "el acto del sensible y el del sentido son un solo y mismo acto, aunque su esencia no sea la misma" (III, 425 a 25 sigs.). Y en lo que concierne a lo inmaterial "hay identidad del pensamiento y de lo pensado, pues la ciencia teórica y lo conocido por ella son idénticos" (III, $43^{0 a} 3$ sigs.). Vale decir que el conocimiento es una coincidencia de las formas que están en el alma con las formas sensibles e inteligibles de las cosas. El alma conoce las cosas en las formas que están en ella y que son idénticas a las formas de las cosas. Por eso lo conocido son las cosas mismas.

La misma doctrina es sostenida en forma más explícita aun por Santo Tomás. Que lo conocido son las cosas mismas, lo dice categóricamente. Respecto al objeto de la sensación, lo exterior capaz de alterar los sentidos es "per se percibido por ellos" (ST. I, $78,3 \mathrm{c}$ ). Y respecto a la intelección: "lo que es entendido no está en el entendimiento tal como es, sino según su imagen (species); como no está en el alma la piedra sino su species según se dice (De An. 431b 29); y, sin smbargo, la piedra misma es lo entendido y no su spe. cies..., so pena de que las ciencias no versaran sobre las cosas sino sobre sus especies inteligibles" (ST. I, 76, 2 ad 4).

En cuanto a la función de la imagen, Santo Tomás es aún más claro, porque no solamente afirma que la species no es más que el medio por el cual el alma conoce las cosas que se hallan fuera de ella, sino que combate expresamente la opinión según la cual el entendimiento no conoce más que su propia modificación, es decir, que el objeto del conocimiento sea la species en el alma, en lugar de las cosas mismas (ST. I, 85, 2c). No nos interesan ahora los fundamentos que aduce Santo Tomás en pro de su interpretación, sino destacar la tesis en sí misma.

Naturalmente, Tomás admite que la species pueda ser objeto secundario del conocimiento por reflexión del entendimiento sobre sí mismo (ST. I, 85, 
2 y 76,2 ad 4). Pero el objeto primario y directo del conocimiento es siempre la cosa. El conocimiento tiene lugar porque "el sujeto cognoscente se asimila a la cosa conocida" (id, $76{ }_{2}$ ad 4 ). En la concepción aristotélicotomista, pues, la imagen no es una copia de la cosa de tal modo que el sujeto conociera la copia en lugar del original, sino algo así como un medium trasparente en el cual el sujeto conoce la cosa, o quizá mejor, el modo o la modificación cognitiva en la cual el sujeto deviene la cosa. La imagen es un medium, pero no una mediación, porque no mediatiza el conocimiento de la cosa, sino que, por el contrario, hace posible su aprehensión directa.

Por eso la palabra "imagen" no es la más adecuada para traducir "eidos" o "species", porque sugiere la idea de aquella mediación.

La función de la species puede hacerse quizá más comprensible comparándola a la de los lentes en un hombre muy miope: interponiéndose entre él y las cosas le permiten la visión de éstas; lo que él ve son las cosas y no precisamente los lentes.

$\mathrm{Si}$, pues, en esta concepción el objeto del conocimiento son las cosas mismas, no sólo no se puede plantear el problema de si existen, sino que sería completamente superfluo el pretender demostrar que existen.

Por eso, si por realismo se quiere entender una teoría que afirma y demuestra la existencia de las cosas fuera (o con independencia) de la conciencia, la gnoseología aristotélico-tomista no es realista porque nunca tentó semejante empresa, empresa que tendría para ella el mismo sentido que la de aquel individuo que habiendo visto una jirafa en un zoo preguntó si un animal asi existía; pero si por realismo se entiende una tesis que afirma que el objeto del conocimiento es la cosa y no su idea, no hay realismo más cabal que éste.

Este realismo puede esquematizarse en la siguiente figura:

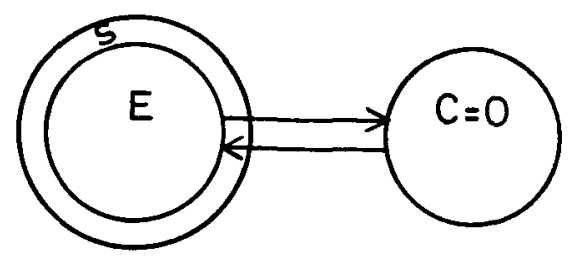

Ahora bien, esta interpretación del conocimiento ha sido completamente trastocada en la filosofía cartesiana. Pues Descartes no sólo distingue entre las cosas y sus imágenes o formas, como Aristóteles y Tomás, sino que, a la inversa de éstos, sostiene que lo que conocemos no son las cosas sino sus ideas en nosotros. En la Medit. III, después de decirnos, que yo no sólo estoy cierto de ser una cosa que piensa sino también de todos los sentimientos e imágenes que se encuentran en mi en cuanto son mis modos de pensar y aunque 
no sean nada fuera de mí y en sí mismas, Descartes advierte que la certidumbre que tenía de otras cosas como la tierra, el cielo, los astros, etc., no era más que aparente, pues lo único que concibe clara y distintamente "no son más que las ideas o los pensamientos de esas cosas que se presentaban a mi espíritu". En cambio, la existencia de cosas fuera de mí, de donde proceden esas ideas y a las cuales éstas fueran totalmente semejantes, es dudosa e incierta, y si es verdad no se basa en un conocimiento evidente. Ahora, pues, el objeto del conocimiento son las ideas, las cogitationes, no las cosas, no el mundo.

Ciertamente, Descartes no fue el primero en enunciar esta doctrina, puesto que ya en la Antigüedad Protágoras y los escépticos (Sext. H. P. I, 99; II, 72) la habian sostenido. Pero mientras éstos no constituyen una tradición en la filosofía occidental, que en la Edad Media los desconoce o los rechaza, la doctrina cartesiana aceptando la doctrina escéptica de la sensación, pero rechazando sus consecuencias, se convierte en el punto de partida del idealismo y en el constante supuesto de toda la filosofía moderna.

Con la tesis cartesiana nace una nueva cuestión. Solamente si el objeto del conocimiento es la idea, tiene sentido preguntar si existen las cosas más allá de la conciencia y si las ideas son semejantes a ellas. Es así como nace el problema de la existencia del "mundo exterior" con todas sus implicaciones, problema desconocido en la filosofía precartesiana.

Es sabido que Descartes resolvió el problema afirmativamente, apoyándose en la veracitas divina; pero de este modo el mundo resulta mediatizado como un conjunto de entes que se encuentran, más allá; o detrás diríamos, de las ideas.

Así, el realismo natural ha sido desalojado por un idealismo psicológico que cabalga sobre un realismo metafísico, en uno de los peores sentidos en que puede usarse esta palabra.

La doctrina cartesiana puede representarse en el siguiente esquema:

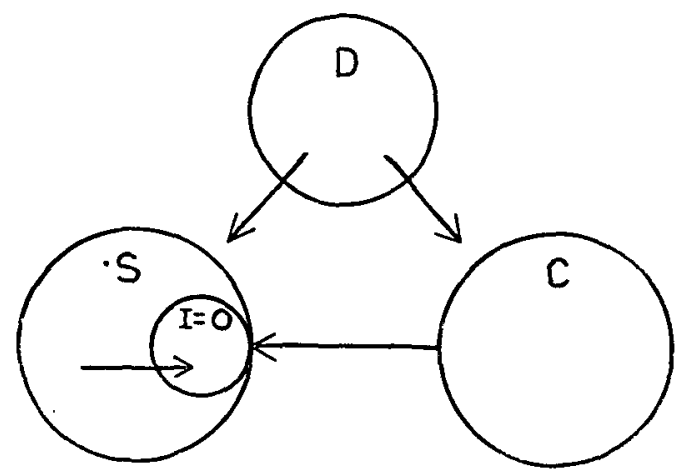


Basta comparar este esquema con el realismo aristotélico para advertir la diferencia esencial: la letra $O$.que designa el objeto del conocimiento ya no se halla en el círculo $C$ (cosa) sino dentro del círculo $S$ (sujeto) e identificada con I (imagen o idea). La garantía de que la idea es copia de la cosa la ofrece Dios, cuya veracitas excluye que el hombre pueda tener ideas claras y distintas a las que no corresponda nada real.

La doctrina cartesiana de la idea-objeto será continuada por los grandes representantes del empirismo inglés.

A pesar de su realismo, Locke sostendrá que los objetos cognoscibles son nuestras propias ideas (Essay II, 8, 8; IV, 1, 1), de donde su definición del conocimiento como concordancia o discordancia entre las ideas (id. IV, 1, 2), y de la verdad, como la expresión en palabras de esa concordancia o discordancia (id. IV, 5, 9).

Berkeley, más consecuente, negará la existencia de sustancias materiales y afirmará no sólo, como sus antecesores, que la idea es el objeto, sino que esta idea-objeto es la cosa misma producida directamente por Dios como contenido de nuestra percepción. Se diría que detrás de toda la argumentación del obispo anglicano hay una aplicación del principio "entia non sunt multiplicanda": si el objeto es la idea y si para asegurarnos que las causas de nuestras ideas son las cosas que no conocemos, hemos de recurrir a la veracitas divina como garantía de su existencia, es más sencillo suprimir ese eslabón intermedio entre nuestras ideas y Dios, reducir la cosa a la idea y conservar la causalidad de Dios, como produciendo directamente las ideascosas en nuestro espíritu.

El esquema de la gnoseología berkeleyana es entonces una simplificación del esquema cartesiano:

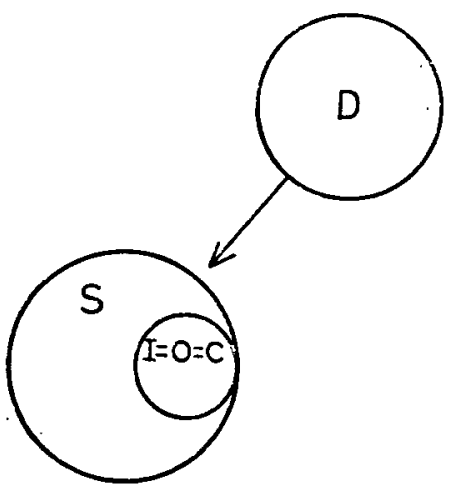

También Hume sostendrá que el objeto del conocimiento son las propias percepciones, sean éstas impresiones o ideas, y que es imposible concebir una idea de algo específicamente diferente de las ideas e impresiones. "Fijemos 
nuestra atención —dice - sobre nosotros mismos tanto como nos sea posible; dejemos caminar nuestra imaginación hasta los cielos o hasta los últimos límites del universo: jamás daremos un paso más allá de nosotros mismos ni jamás concebiremos un género de existencia más que estas percepciones que han aparecido en esta estrecha esfera" (Treat. I, II, 6).

Pero más cauteloso que los anteriores, Hume declara que las causas de nuestras impresiones son desconocidas (id. I, I, 2) e inexplicables (id. I, III, 5) y que, si bien todos los hombres creemos que existen cuerpos con una existencia continua y distinta de nuestras percepciones, esta creencia se origina en nuestra imaginación a cuyas frágiles cualidades no puede concederse fe y que, por tanto, es imposible concebir que los objetos sean algo más que percepciones (id. I, IV, 2).

El idealismo psicológico que Descartes había conciliado con un realismo metafísico, conduce a Hume al escepticismo. Después de haber investigado por todos lados sin hallarle una salida en el ocluso recinto de las percepciones, Hume concluye que "la duda escéptica... es una enfermedad que no podemos curar nunca".

No sólo el empirismo inglés; también la filosofía alemana recoge la tesis de la idea-objeto, pero en ésta, lejos de desembocar en el escepticismo, conduce a la fundación del idealismo trascendental.

Leibniz introduce el concepto de "representación" para sustituir al de idea o imagen en el conocimiento.

Para explicar cómo unas mónadas sin ventanas pueden tener conocimiento de las demás, traslada el concepto jurídico de representación al campo de la filosofia, manteniéndole su sentido jurídico de "estar en lugar de" o "ponerse en el lugar de", como el mandatario representa al mandante. Sólo teniendo presente este sentido puede comprenderse lo que Leibniz quiere decir cuando define a la percepción como "representatio variationis externae in interna" (Comment. de an. brutorum, VIII, Ed. Erdmann, pág. 464), y el significado de la armonía preestablecida cuando dice que "les âmes conoissent les choses, parce-que Dieu, a mis en elles un principe representatif de ce qui est hors d'elles" (A. Clarke, fème. lettre, go. Ed. Erdmann, pág. 757).

El concepto de "representación" se difunde rápidamente y se tornará un término técnico de la psicología y de la filosofía, aunque perdiendo el sentido tan peculiar que le concedió Leibniz y que, desde luego, sólo era compatible con su sistema.

Cuando Kant escribe, la palabra "Vorstellung" es ya tan corriente que no siente necesidad de definirla.

Y no puede negarse que Kant, a pesar de su "refutación del idealismo", a pesar de su declaración de que "el idealismo trascendental es el realismo empírico", afirma reiteradamente que el objeto del conocimiento es sólo el fenómeno, que el fenómeno es nuestra "representación", y que las represen- 
taciones, sean las del sentido externo como las del interno, se dan inmediatamente a nuestra autoconciencia, existen sólo en nosotros y no fuera de nosotros. $^{2}$

Éstas son expresiones literales de Kant que han de ser destacadas al margen de toda la discusión que se ha desencadenado en torno a la interpretación de su doctrina.

Sería superfluo mostrar que en los grandes representantes del idealismo alemán se mantiene la tesis cartesiana, pero en cambio es importante destacar que también el nuevo realismo la conserva. Doctrinas como la de W. Dilthey y $O$. Külpe, si bien sostienen la realidad y la cognoscibilidad del mundo exterior, parten del supuesto de que el objeto dado inmediatamente a la conciencia son sus propios contenidos: sensaciones, percepciones, o "experiencias", que exponen una imagen o símbolo de lo que existe más allá de ellas.

Así, Dilthey en su original intento de superar al idealismo tomando como base en lugar de los solos fenómenos intelectuales, al hombre en su plenitud vital, al descomponer la experiencia de la resistencia en conciencia de impulsos volitivos e intención por un lado, y por otro, en conciencia de un impedimento de la intención, destaca que la conciencia del obstáculo se da siempre a través de una sensación de presión. Este proceso intermedio indica que no hay una experiencia directa de la resistencia, y que, por tanto, la existencia del mundo exterior no se da de modo inmediato, si bien no necesita recurrir a procesos intelectuales (Dilthey, Psicologia y Teoria del conocimiento, FCE, México, págs. 160 y sigs.).

Del mismo modo la múltiple argumentación de Külpe para demostrar que hay cosas reales, que se pueden conocer y cómo se pueden conocer, supone que son los contenidos de conciencia los objetos dados inmediatamente. (Véase Messer, A., El realismo critico, per totum, R.O.).

Este rápido vistazo histórico ha tenido por objeto confirmar que los principales sistemas gnoseológicos modernos, tanto los realistas como los idealistas, tienen como supuesto la tesis cartesiana de que el objeto del conocimiento es un contenido de la conciencia, llámesele idea, imagen, representación, experiencia, percepción o símbolo.

Ahora bien, Husserl, con pleno conocimiento de esta historia, destruye el idealismo psicológico y restituye en sus derechos a la percepción, mostrando que ella tiene un objeto trascendente, una cosa real exterior. Pero esta tesis no es la conclusión de ninguna "prueba" o argumentación, sino el sencillo resultado del análisis fenomenológico y de una precisión conceptual que se adapta rigurosamente a él.

A pesar de que en L.U. Husserl habla con frecuencia de "representa-

2 Véase sobre todo en $K r V$. la conclusión de la estética trascendental y más especialmente aún toda la refutación del $t^{9}$ paralogismo de la razón pura, en la $1^{\mathbf{a}}$ edición. 
ciones", tiene ya clara conciencia del equívoco que implica esta palabra, que una vez puede significar un estado de conciencia, y otra el objeto dado en ese estado. Por eso Husserl distingue el acto o vivencia intencional de su objeto, y así distingue respectivamente el acto de representar de lo representado. Solamente el acto, es decir, el momento hylético-noético es un elemento real de la conciencia, mientras que el objeto, el momento noemático, es irreal en ella, está mentado por ella, pero no forma parte de ella. Por eso cuando se habla de "contenidos" de la conciencia, se emplea un término que proviene de (y conduce a) un error de visión, porque la conciencia no contiene más que sus propios actos; pero los objetos correlativos no están contenidos en ella como en una caja, sino intencionados, mentados por ellos.

De ahi que Husserl sustituya la terminología que distingue entre percepción externa e interna, por otra según la cual los actos se distinguen en trascendentes e inmanentes. Llama "actos de dirección inmanente" a aquellos cuyos objetos intencionales pertenecen a la misma corriente de los actos o vivencias del sujeto, por ejemplo, la reflexión sobre un acto de recuerdo o sobre un placer sensible. En la percepción inmanente, percepción y percepto forman esencialmente una unidad inmediata, una sola cogitatio concreta. El objeto de la percepción sólo puede separarse de ésta por abstracción, pues la percepción inmanente encierra en sí a su propio objeto.

Todos los demás actos, que no tienen esta implicación del objeto en el acto, son actos de dirección trascendente, por ejemplo, los dirigidos a cosas, o a las vivencias intencionales de los otros yos. Así, pues, la percepción trascendente no encierra entre sus momentos reales a su objeto, el cual está fuera de toda unidad esencial con ella (Ideas $\mathrm{I}, \S 38$ ).

Esta distinción entre actos inmanentes y trascendentes es más rigurosa y clara que la kantiana entre intuiciones del sentido externo y del interno, porque no apela a un criterio exterior (el espacio, el tiempo), sino que toma como tal a la propia relación inmediata entre el acto y su objeto.

Partiendo de ella, Husserl no sólo puede afirmar que el objeto de la percepción es la cosa misma, sino también que la tesis que sostiene que su objeto es una imagen o signo es un contrasentido. "Implica, en efecto, que entre trascendente e inmanente no haya ninguna diferencia esencial... Quien tal cree se deja extraviar por la idea de que la trascendencia de la cosa sería la de una imagen o signo. A menudo se combate celosamente la teoria de las imágenes y se la sustituye con una teoria de los signos. Pero tanto la una como la otra no sólo son inexactas sino que entrañan un contrasentido. La cosa espacial que vemos es con toda su trascendencia algo percibido, algo dado en su misma corporeidad a la conciencia...

"Entre percepción, de una parte, y representación simbólica por medio de una imagen o simbólica por medio de un signo, de otra parte, hay una infranqueable diferencia esencial. En estas formas de representación intui- 
mos algo con la conciencia de que es una imagen o signo indicador de otra cosa; teniendo en el campo de la intuición lo uno, no nos dirigimos a ello, sino por intermedio de un concebir fundado, a lo otro, lo reproducido por la imagen o indicado por el signo. En la percepción no se puede hablar de nada semejante. .

"La percepción de cosas no representa algo no presente, como si fuera un recuerdo o una fantasía; presenta, aprehende un ello mismo en su presencia corpórea. Esto lo hace con arreglo a su sentido propio, y pedirle otra cosa significa precisamente pecar contra su sentido." (Ideas I, $\$ 43$ ). ${ }^{3}$

En otras palabras: el objeto de la percepción es la cosa misma, porque la esencia del acto que llamamos percepción, y por la cual se distingue de otros actos, es precisamente la de ofrecer una cosa y no una imagen. Y la doctrina que sostiene que el objeto es la imagen es no sólo falsa sino un contrasentido, porque llamar a algo "imagen" implica saber que hay otra cosa de la cual es imagen, pero si el objeto de la percepción es la imagen, nunca jamás se pudo tener noticia de la existencia de una cosa de la cual aquel objeto fuera la imagen, y por consiguiente, es un contrasentido sostener que es una imagen...

Desde luego que Husserl sabe perfectamente que el acto tiene una materia sensible, el momento hylético, en el caso de la percepción, la sensación, pero distingue entre la sensación como ingrediente de la vivencia y los res. pectivos momentos de las cosas: "Con todo rigor hay que tener presente que los datos de la sensación que ejercen la función de matizar el color, la lisura, la forma, etc. (la función de exhibir) son por principio distintos del color, de la lisura, de la forma, pura y simplemente, en suma de toda clase de momentos de las cosas. El matiz, aunque lleve el mismo nombre, no es, por principio, del mismo género que lo matizado" (Ideas I, \$41).

Ahora bien, Husserl añade expresamente que los "datos de la sensación" ejercen la "función de exhibir", constituyen lo que llamamos el "aparecer de" un color, una forma, etc. (id., id.). Por consiguiente, los datos hiléticos que constituyen las vivencias no se exhiben a sí mismos, sino que exhiben las propiedades de las cosas. El sentido de la percepción es ser una "aprehensión directa" (Erste Philosophie, II T, en Husserliana VIII, página 44 ).

Se advierte, pues, cómo el análisis fenomenológico, fiel al principio de atenerse a lo dado en la intuición, y de describirlo tal como se da, describe la relación de la percepción y su objeto en una forma cuyo resultado, en este punto, coincide con la tesis aristotélico-tomista de que en la percepción conocemos un objeto trascendente, la cosa misma, y no una supuesta imagen,

3 Husserl ha sostenido la misma tesis antes y después de la publicación de las Ideas. Cf. L.U., ed. española, vol. III, pág. 202, y Erste Philosophie, I, T. 17 Vorles. 
que el análisis revela que hay que sustituir por los momentos hyléticos de la sensación, que exhiben sin exhibirse a sí mismos. ${ }^{4}$

El realismo psicológico queda asegurado por la propia evidencia de la intuición de la esencia de la percepción, sin que haya que ejecutar ninguna inferencia, ni desarrollar ninguna prueba, que partiendo de un supuesto objeto inmanente llegara a demostrar la existencia de una cosa en sí, trascendente.

Toda ciencia tiene que partir de la concepción realista del mundo, de la cual ella es sólo una modificación y nunca una total sustitución.

Jamás Husserl ha gastado una línea en demostrar que existe el mundo o que sea directamente cognoscible. $Y$ en su última obra se ha expresado al respecto del modo más claro y ha designado este momento de su descripción con el término expreso de "realismo". "Por adelantado está el mundo, siempre en certeza de ser y autoverificación, dado de antemano y fuera de duda... está para mí... en vigor... con todo lo que es para mí.., también con todas las ciencias, artes, con todas las formas de instituciones sociales, personales, en cuanto justamente es el mundo que para mí es el real. Por tanto, no puede darse un realismo más fuerte, si esta palabra no significa más que: yo estoy seguro de ser un hombre que vive en ese mundo, etc., y no dudo de ello en lo más mínimo" (Krisis. Husserliana VI, pág. 1go y sig.).

La condicionalidad de la última frase quiere dejar a salvo el idealismo trascendental que sostiene Husserl, punto sobre el cual hemos de volver.

Se podría objetar que a la base de la epojé husserliana se halla la duda sobre el mundo. Y efectivamente, en las Meditaciones Cartesianas, el método adopta este sesgo sin una fundamentación detallada y con una somera referencia a Descartes.

Sin embargo, existen diferencias netas de sentido, de alcance y de motivación entre la duda cartesiana y la duda husserliana.

Hay que conceder a Descartes el honor de haber ejecutado la duda, aunque sólo fuera como intento o ficción, con una radicalidad a la cual Husserl, deliberadamente, es ajeno. Descartes duda que el mundo que efectivamente es sea efectivamente, es decir, que el mundo hic et nunc real sea real. Y no solamente duda, sino que convirtiendo la tesis de la actitud natural en antítesis, declara a las cosas falsas, supone que todo lo que está fuera del cogito, no existe, mientras no pueda cerciorarse de su existencia. ${ }^{5}$

4 Dejamos de lado ahora la esencial inadecuación que caracteriza a la percepción, porque ella no modifica para nada la validez de la tesis principal.

5 Recuérdense los dos conocidos pasajes: “... es necesario que detenga y suspenda en adelante mi juicio sobre esos pensamientos, y que no les conceda más crédito que el que daria a cosas que me parecieran evidentemente falsas" (Medit. I, Ed. Gallimard, pág. 164). "Supongo, pues, que todas las cosas que veo son falsas; me persuado de que nada jamás ha sido de todo lo que mi memoria henchida de mentiras me representa... Creo que el cuerpo, la figura, la extensión, el movimiento y el lugar no son más que ficciones de mi espíritu" (Medit. II, id., pág. 166) . 
Y para fundamentar esa duda hiperbólica, de un modo más sólido que el que le ofrecen el error, la ilusión y los ensueños, apela a la hipótesis de un genio maligno que hiciera parecer. ante el espíritu lo que no es. Con una inconsecuencia tiene que pagar Descartes su extremo radicalismo, pues para tener un motivo decisivo de la duda y de la negación de lo que está fuera del cogito, tiene que suponer la existencia de algo fuera del cogito.

Nada de esto hallamos en Husserl. Ciertamente que vincula su método con el intento de duda universal de Descartes. Pero Husserl sólo lo emplea como instrumento metódico para destacar el punto que realmente le interesa, que es el de deslindar el campo de las evidencias apodícticas de aquellas que no lo son. No solamente no niega la existencia del mundo, sino que ni siquiera ejecuta la duda efectiva de que el mundo que realmente es y es dado sea. No hay motivos racionales para dudar frente a la enorme fuerza de las experiencias coherentes. La epojé suspende todos los juicios de existencia sobre el mundo, desconecta la tesis de la actitud natural o, según su peculiar expresión, la pone "entre paréntesis". Pero la tesis sigue existiendo como lo desconectado sigue existiendo fuera de la conexión. Lo que Husserl sostiene es que es concebible una duda, "porque jamás queda excluida la posibilidad de la no existencia por ser una posibilidad de principio" (Ideas I, $\S \S 31,32$ y $4^{6}$ ).

¿Cuál es el alcance de esta última frase?

Las explicaciones más claras las ofrecen las lecciones sobre la Filosofia primera, dictadas en los semestres de $1923 / 24$ y publicadas recientemente (Erste Philosophie, en Husserliana, volúmenes VII y VIII).

Si confrontamos estas dos proposiciones: "yo soy" y "el mundo es", ambas, desde luego, verdaderas, hallamos una diferencia respecto a su validez, pues mientras la primera tiene necesidad apodíctica, la segunda es contingente. La esencial inadecuación de la percepción, en cuanto sólo puede presentar una faz de la cosa mientras el resto ha de ser presumido; la posibilidad de que cada percepción sea una ilusión; el hecho de que la armonía de experiencias en las cuales se da el mundo pudiera disolverse en la incoherencia, todo esto conduce a la conclusión de que el mundo podría ser de otro modo e incluso no ser, y por tanto que el ser de la experiencia no puede tener necesidad apodíctica (Huserliana VIII, págs. 44 sigs.).

Evidentemente cada hecho y, por consiguiente, también el hecho del mundo es contingente. Pero para la existencia del mundo se plantea una contingencia peculiar, una contingencia cognitiva, de sentido: que aunque el mundo me sea dado de modo que no pueda dudar de su existencia, su darse presencialmente nunca excluye su no ser.

La cuestión puede ser aclarada desde otro ángulo. Hay que distinguir dos clases de indubitabilidad. Una significa: no dudo ni puedo dudar cuando nada habla contra una existencia dada. Pues la duda ha de fundarse en 
algo que hable en contra. En este sentido, el mundo es indubitable. La otra es la falta de duda apodíctica. Significa que ni siquiera puedo pensar la posibilidad de que lo percibido no sea. Tal es el caso cuando me pienso a mí mismo: mi subjetividad trascendental es impensable como no siendo. En cambio, ello no ocurre con el ser de la experiencia exterior: se puede pensar que lo percibido no sea. En esto consiste la contingencia de la proposición "el mundo es" (Husserliana VIII, pág. 5o).

El resultado del análisis de Husserl no es que "el mundo que percibimos quizá no sea". Por el contrario, repite aquí como en otros lugares que "la existencia del mundo está completamente fuera de duda". Pero se trata de otra cosa: esa falta de duda empírica deja abierta la posibilidad de que, a pesar de todo, el mundo no sea, posibilidad que subsiste, aunque nada hable a favor de su realización.

De ahí concluye que con nuestra seguridad perceptiva indudable de la existencia del mundo es compatible la proposición de que el mundo sea una pura nada, una apariencia trascendental. De donde, el principio hipotético de la no existencia del mundo no es una proposición hipotética arbitraria, como el contrasentido de $1>2$. En el caso del mundo se trata de una hipótesis evidentemente posible, inteligible sin contrasentido (Husserliana VIII, pág. 54 sig.).

Aquí es muy posible un malentendido que hay que disipar. Perceptivamente el mundo es indudable. Se estaría tentado de pensar que la compatibilidad con esa tesis, de la otra de que el mundo no sea, proviene de que esta última sea entendida como contingencia ontológica del mundo, es decir, que al mismo tiempo que el mundo de mi percepción tiene una existencia de hecho, no tiene una existencia necesaria, proposiciones ambas verosímilmente ciertas y compatibles. Pero no es ése el pensamiento de Husserl. Por más que haya aquí un sutil matiz, es importante destacarlo. La contingencia del mundo es no sólo ontológica, sino gnoseológica, trascendental en cuanto puedo pensar sin contradicción su no-ser. Lo cual no ocurre con el cogito. Lo que aqui se pone en claro es la concebibilidad del no ser del mundo, que sustrae a la proposición "el mundo es" el carácter de evidencia apodíctica.

Tratemos ahora la otra objeción que surge naturalmente. ¿Cómo puede pretenderse que la filosofía de Husserl sea una contribución al realismo cuando ella misma es no sólo en su contenido efectivo idealista, sino que expresamente se da a sí misma el título de Idealismo, y se caracteriza como filosofía trascendental?

Para tratar esta difícil cuestión es muy oportuno tener presente cuál ha sido la intención de Husserl, la preocupación que lo ha guiado a través de su meditación filosófica.

Cuando después de las L.U. Husserl comienza su empresa filosófica en gran escala escribe en su diario de notas el 25.9.906 estas líneas: 
“En primer lugar menciono la tarea general, que he de resolver para mí, si he de poder llamarme filósofo. Quiero decir una crítica de la razón. Una crítica de la razón lógica y práctica, de la valorante en general. Sin haberme hecho claro en rasgos generales el sentido, esencia, métodos, puntos de vista principales de una crítica de la razón; sin haber pensado, proyectado, fijado y fundado un proyecto universal para ella no puedo vivir real y sinceramente" (Husserliana II, págs. vir y sig.). Y treinta años más tarde, cuando la empresa ya ha dado sus rendimientos, consigna otra vez su problema, ahora en los términos concretos que implica el método ya descubierto: "No se trata de asegurar la objetividad, sino de comprenderla. Hay que advertir que ninguna ciencia objetiva, por más exacta que sea, explica o puede explicar seriamente algo. Deducir no es explicar. Predecir o conocer formas objetivas estructurales de cuerpos físicos o químicos y según ellas predecir, todo eso no explica nada, sino que necesita explicación. La única explicación real es: hacer comprensible trascendentalmente. Todo lo objetivo está bajo la exigencia de la comprensibilidad" (Kr., pág. 193. Cf. Kant. Husserliana VII, pág. 247).

El problema de Husserl es, pues, ante todo, en términos generales, el problema gnoseológico-trascendental, no un problema ontológico ni cosmológico. Se trata de hacer comprensible al mundo en "el cómo de sus modos de darse", no de averiguar su estructura ni su devenir (Kr., pág. 163).

El idealismo de Husserl ha sido interpretado en diversas formas porque él mismo oscila en el alcance que le otorga y sus expresiones no están siempre exentas de todo equívoco. No se nos podrá exigir, pues, una interpretación libre de todo error. Por eso los pasajes que acabamos de citar han de servirnos de pauta en una interpretación que no quiera sobrepasar las intenciones originarias y permanentes que el filósofo puso en su obra. El idealismo de Husserl no es sólo idealismo metodológico que destaca el modo apodíctico de la certeza de la conciencia y de todo ser inmanente frente al modo problemático del mundo y de todo ser trascendente (id. I, $\S \lessgtr 46,49$ ).

Tampoco es sólo un idealismo gnoseológico, en el sentido del "principio de la conciencia" (Reinhold), implícito o explícito en toda la tradición cartesiana, según el cual la conciencia sólo conoce sus propios contenidos, pero que al mismo tiempo admite cosas en sí que están más allá de ellos, y con las cuales ellos tuvieran que concordar, para tener significación objetiva.

Justamente contra este modo de ver se levanta Husserl descubriendo su contrasentido. Por un lado, como ya lo hemos visto, mostrando que la percepción aprehende la cosa misma y no a una imagen o signo; por otro, destacando que la pregunta por la validez objetiva, si se hace en la actitud natural, ya contiene la respuesta, pues al ponerme como hombre ya he apercibido al mundo espacial, dentro del cual me hallo situado con un "fuera de mi" (C.M., 41). 
A partir de las Ideas y en forma cada vez más constringente, ${ }^{6}$ Husser defiende un idealismo absoluto, estricto, sin resto, al estilo de Fichte. No solamente no conocemos nada más que lo que está en la conciencia, sino que no hay nada fuera de la conciencia. Pero lo que hay en la conciencia es nada menos que el mundo mismo y las cosas.

Las cosas son siempre correlatos de la conciencia real y posible. La trascendencia no significa ser independiente de la experiencia, sino que su concepto mismo sólo se puede formar del contenido de la percepción, o de la experiencia comprobatoria. "Jamás es un objeto existente en sí un objeto tal que no le afecte para nada la conciencia y mi yo."

Sin duda no existe sólo lo que es objeto de experiencia actual, sino también lo posible, lo no experimentado, pero tiene que estar vinculado a la experiencia por un orden de motivación (id. I, $\$ 47$; C.M., 30).

Pero la dependencia señalada no está referida a la conciencia empírica, sino a la conciencia trascendental, que resulta de la epojé ejecutada en todos los órdenes de las trascendencias, por consiguiente, no sólo del mundo empírico, sino también de mi ser humano y de mi yo psíquico, del mundo de la física, de los yo ajenos, del mundo de la cultura y de Dios mismo.

Ahora bien, la epojé no anula al mundo, porque su operación consiste en suspender el juicio categórico de la conciencia ingenua sobre la existencia del mundo, pero no puede echar abajo los datos de la intuición. Después de la epojé el mundo sigue siendo trascendente al yo, pero ahora como objeto intencional de la conciencia, como trascendencia inmanente ( $C . M ., 11$ ).

Por tanto, la conciencia pura es un orden del ser encerrado en sí, un orden de ser absoluto, en el que nada puede entrar ni. salir. No tiene un exterior espacio-temporal, ni está dentro de un espacio-tiempo (id. $1, \S 49$ ).

De modo muy gráfico lo expresa Husserl en otro lugar: "La experiencia no es un agujero en un espacio consciente en el que un mundo existente antes de toda experiencia, apareciera, o un mero meter dentro de la conciencia algo ajeno a la conciencia. Pues ¿cómo podría yo enunciar eso racionalmente sin verlo y por lo tanto cómo la conciencia ve así lo ajeno a la conciencia y por lo tanto lo experimenta?" (FTL, pág. 206).

La conciencia, pues, alberga en sí todo lo que es, todas las transcendencias del mundo (id. I, $\$ 50 ;$ C.M., 41).

Lo que Husserl niega no son las cosas ni el mundo de la experiencia, sino el realismo metafísico, la teoría que concibe el conocimiento suponiendo una trascendencia "metafísica" que por medio de una causalidad "metafisica" injertara dentro de la subjetividad una imagen cognitiva.

La tesis kantiana (pero ya implícita en Descartes) de un mundo de cosas en sí incognoscibles, que estuvieran detrás y que causaran las cosas de la expe-

6 Destinada a convencer a sus reacios discipulos realistas (cf. E. Stein, Husserls Festschrift, 1929, págs. 326 y sig.). 
riencia, no sólo carece de fundamento, sino que es un contrasentido, pues sería un sentido desgarrado del lugar originario de todo sentido. La conciencia no puede sufrir causalidad de parte de ninguna cosa. (Kant. Husserliana VII, pág. 248; Nachwort, Jahrbuch XI, págs. 559 y 563; id. I, §52; C.M., 41; id. I, § 49).

Pero esta negación del realismo metafísico, no significa de ningún modo disolver la realidad de las cosas en lo psíquico, convertir al mundo en fenómenos subjetivos, como Berkeley y Hume lo hicieron. El idealismo psicológico es negado no menos enérgicamente que aquel realismo de las cosas en sí. (id. I, § 152, 55; Kant. Husserliana VII, pág. 246; Nachwort, Jahrbuch XI, págs. 549 sig. y 563 ).

Pues las cosas no forman parte real (reell) de las vivencias, sino que se hallan en la conciencia "idealmente", como objetos intencionales, como cosas que "aparecen", como "sentido objetivo".

Es solamente a este aspecto de la concepción de Husserl, a la determinación del alcance de la intencionalidad y de la constitución trascendental, a que debe limitarse su oscilación entre una formación de sentido y una creación del ente, y por consiguiente, a la doble interpretación a que puede dar lugar.7 Esta cuestión debe ser distinguida de la otra, con la cual generalmente se confunde, y que hemos tratado antes, a saber, si son las cosas mismas o sus imágenes las que se hallan en la conciencia. Sobre este punto no puede caber duda de que la filosofía trascendental de Husserl es un idealismo estricto, como el de Fichte. Pero esto no implica que haya de ser interpretado necesariamente, como quería Fichte, como un idealismo productivo del ente.

Hay que destacar aquí, ante todo, que para Husserl la conciencia no sólo no puede sufrir causalidad, sino que tampoco puede ejercer causalidad sobre ninguna cosa (id. I, §49).

Cierto que la intencionalidad no es un neutro estar dirigido hacia el objeto, sino una operación, un producir por las nóesis, pero lo producido no es la realidad bruta del ente, sino la unidad y el sentido del objeto en la sintesis de la conciencia (id. I, §§ 85, 88; C.M. 18, Krisis, pág. 171).

La idea directora que Husserl tiene a la vista siempre es que el conocimiento, o mejor dicho lo conocido es incomprensible por una acción de la cosa sobre la conciencia, lo que supondría que la conciencia a su vez es una cosa, y conduciría en definitiva a un absurdo materialismo, sino por el contrario, que lo conocido como conocido tiene su fuente última en la conciencia misma, que es ésta la que "hace consciente" al ente, la que lo "da a conocer", en la que, gracias a la intencionalidad y a los actos constituyentes, el ente "es revelado" en su ser y en sus rasgos esenciales. (Id. I, $\S \S 86,76,97,117$; id. II,

7 Véase Fink, E., ẹn Problèmes actuels de la Phènoménologie, Desclée, 1952, pág. 78 , y Landgrebe, en Les Etudes Philosophiques, 1954, págs. 317 y sigs. 
§ 55; Part. Vort. en Husserliana I, pág. 24; Kant, Husserliana VII, págs. 247 , 251, 272).

Esta operación es la maravilla, el milagro de la conciencia, por lo cual reconocemos en ella algo absolutamente diferente de todo otro ente.

Por eso dice Husserl que ésta es "la única solución concebible de los problemas más profundos del conocimiento, los concernientes a la esencia y posibilidad de un conocimiento objetivamente válido de lo trascendente" (id. I, $§ 97$ ).

Un sentido sólo lo puede dar la conciencia. Incluso las supremas categorías de ser y no ser, ser real, ideal, ficto y sus modalidades dóxicas son sentidos constituidos en la conciencia.

Que el problema sea para Husserl el de la génesis fenomenológica o si se quiere gnoseológica, como un aspecto de aquélla, y no el de una génesis óntica, resulta también de que la teoría de la constitución como tal no tiene carácter creador, sino trascendental, el de ser una "típica" de a priori subjetivos correspondiente a la típica de las regiones del ser trascendente. (Id. I, $\S 86$; FTL, pág. 222; C.M. 21).

Pues también el yo ajeno e incluso Dios son lo que son para mí constituidos en una operación de mi conciencia. Y agrega Husserl decisivamente refiriéndose a Dios: "También aquí... 'operación de la conciencia' no quiere decir que yo invente o fabrique esa suprema trascendencia" (FTL, pág. 222). Más aún: mi propio yo es constituido en mí mismo, lo que nos obliga a distinguir todavía entre la subjetividad trascendental y el yo puro como polo absoluto de toda constitución (C.M. IV y Krisis, pág. 189 sig.). Estos casos ponen de manifiesto el absurdo que sería interpretar la intencionalidad y la constitución como creando a los entes.

El idealismo de Husserl es un idealismo del sentido. El mundo, el hombre, el yo empírico humano, son un ser intencional por su sentido puesto por la conciencia pura gracias a que sus intencionalidades pueden converger en un objeto idéntico en la multiplicidad de sus modos de darse (id. I, § 49). Por eso la tarea central de la fenomenología es una tarea retroactiva que parte del objeto dado y marcha hacia la explicitación de las intencionalidades actuales y potenciales en las cuales aquél logra su sentido de ser. El idealismo así concebido no sólo no niega la realidad del mundo, sino que la hace comprensible.

"El idealismo fenomenológico no niega la existencia efectiva del mundo real (y ante todo de la naturaleza) como si opinara que es una apariencia, a la que estuviera sujeto el pensamiento científico positivo sin advertirlo. Su única tarea y obra es aclarar el sentido de ese mundo, exactamente el sentido en el cual vale para cada cual como siendo efectivamente, y con qué derecho efectivo vale. Está completamente fuera de duda que el mundo existe, que él está dado como universo existente en la experiencia continua 
que converge siempre en unanimidad universal" (Nachwort, Jahrbuch XI, pág. $5^{62}$ ).

La paradoja de que el mundo entero sea una figura de sentido constituida por el sujeto cuando éste mismo es una parte del mundo se disuelve si se considera que los sujetos, yo, nosotros, tienen distinto significado: 1 ) las cosas son exteriores a los hombres e independientes de ellos en cuanto sujetos psicofísicos con su vida anímica humana. Aquéllas y éstos son objetos naturales, realidades intramundanas. 2) todas esas realidades, el mundo entero, incluso yo mismo como hombre, son fenómenos, correlatos objetivos de las intencionalidades que les conceden su sentido de ser. Pero los sujetos que operan su constitución no son los hombres, sino los sujetos puros, trascendentales, los yo-polos residuales después de ejecutada la epojé.

Aun cuando se establezca una diferencia entre objetos en sí y objetos conocidos, aun cuando el ser-en-sí del mundo sea un hecho indubitable, aquella diferencia y este "hecho indubitable" son predicados que hacemos nosotros y que como tales sacan su sentido del conocimiento, de la subjetividad trascendental (Kant. Husserliana VII, págs. 247, 277 y sigs.; Krisis, págs. 183,186 y sig.). De un objeto mentado podemos decir que es "real verdaderamente", cuando su posición se basa en un sentido lleno, que da originariamente, cuando es susceptible de una comprobación que ocurre en la experiencia efectiva, originaria, adecuada y concordante (id. I, $\$ \S 136,140$, 142, 152. C.M. III). Todo lo cual ocurre, desde luego, en la inmanencia de la conciencia pura.

Así, pues, el ser del mundo objetivo en la actitud natural y esta misma no han perdido nada por el hecho de que sean comprendidos retroactivamente en la subjetividad trascendental (Krisis, pág. 193). Al contrario, gracias a ella y en ella podemos dar sentido a lo real, a la verdad y distinguirlas de lo ficto y de lo falso.

El idealismo de Husserl es una "teoría trascendental del conocimiento trascendente". "El mundo con todas sus realidades, y dentro de ellas, mi ser real humano es un universo de trascendencias constituidas" (FTL, 222, 223, C.M. $\S 28,41$ ).

Podría preguntarse ahora si después de todo análisis y descripción llevados a cabo en la conciencia pura mediante la epojé, no habrá finalmente que anular a ésta, sacar el paréntesis, para volver a la actitud natural y fijar resultados y conclusiones definitivas sobre el mundo. Pero esta preocupación es injustificada y revela que nada se ha entendido. La epojé se lleva a cabo por la necesidad de comenzar un conocimiento absolutamente justificante contra el cual conspira el "prejuicio del mundo" porque los juicios categóricos sobre la existencia de las cosas son, en la actitud ingenua, acríticos. Pero como la epojé no anula a los entes sino que los revela como objetos intencionales para la conciencia pura, será luego en virtud de la explicitación de 
las intencionalidades y de la retroacción hacia la constitución trascendental cuando podrán enunciarse juicios sobre el ser real del mundo, sobre el ser o no ser de los objetos, esta vez precisamente fundados, y fundados en una comprensión evidente incomparablemente nueva e insuperable (véase una nota de 1924 en Husserliana VIII, pág. 481 y sig.).

Lo que había de enunciados verdaderos (si así se puede hablar) en la actitud natural será cabalmente confirmado y convalidado en la actitud fenomenológico-trascendental.

La epojé no debe ser suprimida, porque la epojé se elimina automáticamente, como un purgante, al eliminar los prejuicios de la actitud ingenua. Pero el organismo purificado, la conciencia pura y el mundo trascendente como su correlato intencional permanecen.

El idealismo de Husserl no debe, pues, ser entendido como una teoria idealista en contraposición a otra teoria realista, que se disputaran el triunfo con argumentos más o menos convincentes. Significa más bien la superación de esa disputa. Es lo que quiere decir Husserl cuando califica su propia filosofía de "idealismo universal" (Nachwort, pág. $5^{61}$ ).

Pero su interpretación debe precaverse contra representaciones engañosas que pueden ser sugeridas por la connotación especial del lenguaje. Así, cuando Husserl dice que la conciencia pura es un orden de ser "encerrado" en sí, o que "alberga en si" al mundo, como si todavía pudiera existir un "afuera" de ella. O cuando habla de los "contenidos" de la conciencia, como si ella fuera una caja dentro de la cual estuvieran las cosas. Que el mundo está en la conciencia, significa que la conciencia es ya con el mundo, que ella es el ser excepcional y privilegiado que por la intencionalidad puede llegar a lo que no es ella sin la indicación de un camino que vaya de la inmanencia del acto a la trascendencia del objeto, el cual es revelado en la intuición y al cual puede conferirle un sentido el pensamiento. Trascendencia e inmanencia son correlatos indisolubles. No hay inmanencia sin trascendencia, ni trascendencia sin inmanencia. La conciencia, pues, no es un ser cerrado que dejara afuera algo, sino por el contrario, el ser abierto a todo, el ser omniabarcante. Puede decirse, pues, que Husserl contiene ya en germen a Heidegger.

La epojé no significa hacer un tajo en la trascendencia, partiéndola en dos y dejando adentro la imagen y afuera la cosa. La realidad "de verdad", el mundo "objetivo" es aquel que es dado en la subjetividad y en la intersubjetividad trascendental en experiencias confirmatorias de evidencias, por cierto no apodicticas pero sí adecuadas, de suerte que la razón pueda conferirle su sentido de ser.

Husserl no diseca el mundo para reducirlo a algo menos de lo que en realidad es, sino que, por el contrario, su operación filosófica consiste en ampliar el poder de la conciencia hasta hacer de ella el lugar de todo ente 
y la cesora de todo sentido. Es una nueva versión del principio aristotélico de que "el alma es en cierto sentido todo".

La filosofía de Husserl, entonces, es un realismo más integral que todo realismo, a partir de Descartes, porque es un idealismo más integral que todo otro idealismo.

Juan Llambías de Azevedo 